\title{
4-acetamido-2,2,6,6-tetramethylpiperidine-1-oxyl as a model organic redox active compound for nonaqueous redox flow batteries
}

\author{
Jarrod D. Milshtein ${ }^{\mathrm{a}, \mathrm{b}}$, John L. Barton ${ }^{\mathrm{a}, \mathrm{c}}$, Robert M. Darling ${ }^{\mathrm{a}, \mathrm{d}}$, Fikile R. Brushett ${ }^{\mathrm{a}, \mathrm{c}^{*}}$ \\ a Joint Center for Energy Storage Research \\ ${ }^{b}$ Department of Materials Science and Engineering, Massachusetts Institute of Technology, Cambridge, MA 02139 \\ ${ }^{c}$ Department of Chemical Engineering, Massachusetts Institute of Technology, Cambridge, MA 02139 \\ ${ }^{d}$ United Technologies Research Center, East Hartford, CT 06108
}

\section{0. $\quad$ Abstract}

Nonaqueous redox flow batteries (NAqRFB) that utilize redox active organic molecules are an emerging energy storage concept with the possibility of meeting grid storage requirements. Sporadic and uneven advances in molecular discovery and development, however, have stymied efforts to quantify the performance characteristics of nonaqueous redox electrolytes and flow cells. A need exists for archetypal redox couples, with well-defined electrochemical properties, high solubility in relevant electrolytes, and broad availability, to serve as probe molecules. This work investigates the 4-acetamido-2,2,6,6-tetramethylpiperidine-1-oxyl (AcNH-TEMPO) redox pair for such an application. We report the physicochemical and electrochemical properties of the reduced and oxidized compounds at dilute concentrations for electroanalysis, as well as moderate-to-high concentrations for RFB applications. Changes in conductivity, viscosity, and UV-Vis absorbance as a function of state-of-charge are quantified. Cyclic voltammetry is performed to investigate the redox potential, reversibility, and diffusion coefficients of dilute solutions, while symmetric flow cell cycling is employed to determine the stability of the AcNH-TEMPO redox pair over long experiment times. Finally, single electrolyte flow cell studies are performed to demonstrate the utility of this redox couple as a platform chemistry for benchmarking NAqRFB performance.

Keywords: nonaqueous redox flow battery, Bobbitt's salt, TEMPO, flow cell, energy storage

${ }^{*}$ Corresponding author. Tel. +16173247400

Email address: brushett@mit.edu (F. Brushett) 


\section{Introduction}

Electrochemical energy storage will play a key role in facilitating the de-carbonization of the electrical power sector by enabling the penetration of intermittent renewable resources and improving the energy efficiency of the electric grid through a series of high value services. $[1,2]$ Redox flow batteries (RFBs) are attractive electrochemical devices for grid storage applications due to independent scaling of power and energy, long service life, and simple manufacturing, [36] but present high costs prevent widespread deployment. [5,7] Recent research efforts have focused on identifying new organic active materials [8-14] and nonaqueous solvents, which enable high cell potentials $[7,15,16]$ and high cell energy densities, as a pathway towards low cost redox electrolytes (solutions comprised of active species, salt, and solvent). While organic active materials in nonaqueous electrolytes appear to offer a viable route toward next generation RFBs, the field is nascent and many critical system properties remain unexplored. To date, most research activities have focused on molecular discovery and electrochemical characterization under dilute conditions. [8,9,11] Such studies provide valuable information relating to fundamental electrochemical properties (e.g., redox potential, rate constant) but do not offer much insight to the solution properties (e.g., viscosity, conductivity) of redox electrolytes containing moderate-to-high concentrations of active materials. The knowledge gap in redox electrolyte properties, at moderateto-high concentrations, leads to uncertainty in how to effectively design flow cells for nonaqueous RFBs (NAqRFBs); in particular, the increased viscosities and decreased conductivities associated with nonaqueous redox electrolytes, in comparison to aqueous systems, offer a new set of obstacles. To date, reported NAqRFBs show poor performance and durability, but identifying performance-limiting factors is challenging as cell failure may relate to either active species degradation (e.g., instability, insolubility, incompatibility) or shortcomings in flow cell design (e.g., crossover, membrane degradation, high resistance). Disentangling the effects of a new active species and cell design in NAqRFB studies can be difficult, and, as such, advancing cell engineering for NAqRFBs requires systematic investigations of redox electrolytes containing near practical active species concentration with well-understood electrochemical and physicochemical properties.

Platform redox chemistries are needed for controlled studies of nonaqueous redox electrolyte properties and associated flow cell performance characteristics. For example, aqueous RFB studies 
have exploited the $\mathrm{VO}^{2+} / \mathrm{VO}_{2}{ }^{+}$redox couple to study cell performance as a function of cell configuration [17,18] and spatial variation of solution properties in the reactor. [19] To be considered for such applications, a redox active species must be stable over multiple cycles, soluble in the electrolyte of interest ( $\geq 0.5 \mathrm{M}$ in organic electrolytes), and readily available in the reduced and oxidized states. Ideally, such a redox couple would be commercially available in both oxidation states, considering that chemical or electrochemical redox syntheses can be time and materials intensive, and may introduce impurities. Several candidate materials for NAqRFB studies are viologens, ferrocene, or 2,2,6,6-tetramethyl-1-piperidinyloxy (TEMPO). Viologens offer multi-electron transfer behavior with fast kinetics, [20] but exhibit low state-of-charge (SOC) dependent solubility and are not readily available in the reduced state. Ferrocene also has stable electrochemical performance [21] and is commercially available (Sigma Aldrich) as both ferrocene and ferrocenium, but ferrocene still suffers from low solubility $(<0.2 \mathrm{M})$. [22] Finally, TEMPO is a stable, soluble active species with facile kinetics, [10] but is not commercially available in its oxidized form.

A TEMPO analogue, the 4-acetylamino-2,2,6,6-tetramethyl-1-oxo-piperidinium cation $\left(A c N H-T_{E M P O}\right)$, which is typically paired with a tetrafluoroborate anion ('Bobbitt's Salt'), is an oxoammonium ion commonly used as a chemical oxidant. [23-32] The simpler TEMPO molecule also has a variety of oxidant applications, but the synthesis procedures of and precursors to AcNH$\mathrm{TEMPO}^{+}$are cheaper, leading to the commercial availability of AcNH-TEMPO ${ }^{+}$. [32] The neutral 4-acetylamino-2,2,6,6-tetramethyl-1-oxo-piperidinium (AcNH-TEMPO) radical molecule is relatively easy to synthesize [32] and is also commercially available as an electron spin resonance spectroscopy standard. [33] TEMPO, and many of its derivatives, have been explored for their electrochemical properties, [34-38] with applications in overcharge protection, [39-41] solid electrodes for stationary batteries, [42,43] and flowing redox electrolytes. [10,44-48] While, in general, the electrochemical behavior of TEMPO-derived molecules appears extensively studied, the properties of AcNH-TEMPO have only been evaluated in aqueous conditions, for dyesensitized solar cells, [49] and remain unreported in nonaqueous conditions.

We propose the AcNH-TEMPO / AcNH-TEMPO ${ }^{+}$redox pair (Figure 1) as a commercially available, organic redox active couple to serve as a platform chemistry for systematic NAqRFB studies. First, the viscosity, conductivity, density, and spectral properties of redox electrolytes 
containing AcNH-TEMPO are measured as a function of SOC. Second, the electrochemical properties of the AcNH-TEMPO redox pair are investigated. Cyclic voltammetry (CV) provides an initial electrochemical investigation of both AcNH-TEMPO and AcNH-TEMPO ${ }^{+}$to identify redox potential and reversibility. Third, symmetric flow cell cycling determines the capacity retention of both AcNH-TEMPO species. Finally, we embark on single electrolyte flow cell studies, $[17,18]$ with higher concentrations of the AcNH-TEMPO redox pair, to demonstrate NAqRFB reactor performance and quantify performance-limiting factors. Ultimately, these investigations present AcNH-TEMPO as a viable model redox chemistry, which can be used as a tool for NAqRFBs performance diagnostics.

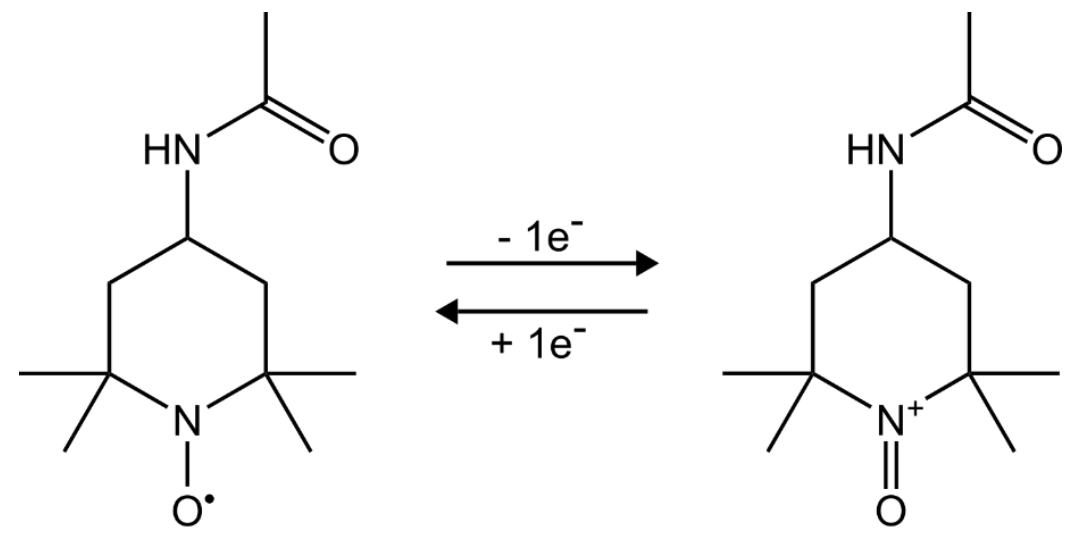

Figure 1: Schema of the redox reaction between AcNH-TEMPO and AcNH-TEMPO ${ }^{+}$. The counter ion in this work is $\mathrm{BF}_{4}^{-}$.

\section{Experimental}

\subsection{Materials, Equipment, and Uncertainty Analysis}

4-acetamido-2,2,6,6-tetramethylpiperidine-1-oxyl (AcNH-TEMPO, $97 \%$ ) and 4-acetylamino2,2,6,6-tetramethyl-1-oxo-piperidinium tetrafluoroborate $\left(\mathrm{AcNH}^{-\mathrm{TEMPO}^{+},} 97 \%\right.$ were purchased from Sigma-Aldrich and used as received. For electrochemical experiments, lithium tetrafluoroborate $\left(\mathrm{LiBF}_{4}, 99.9 \%\right)$, and propylene carbonate (PC, $\left.99.99 \%\right)$ were purchased from BASF and used as received. For spectroscopy experiments, $\mathrm{LiBF}_{4}(99.99 \%)$ and PC (99.7\%) were purchased from Sigma-Aldrich; PC was dried and stored over molecular sieve beads (Sigma Aldrich, 3A) for at least $12 \mathrm{~h}$ before use. Lithium metal foil (99\%) was purchased from Alfa Aesar. 
While AcNH-TEMPO and AcNH-TEMPO ${ }^{+}$are indefinitely stable in air, [32] nitroxyl radicals and oxoammonium cations are known to undergo complex side reactions in water. [48] As such, all solution preparation, chemical storage, and electrochemical experiments were performed in an argon-filled glove box $\left(\mathrm{O}_{2}<1 \mathrm{ppm}, \mathrm{H}_{2} \mathrm{O}<0.5 \mathrm{ppm}\right)$ from Inert Technology, maintained near 25 ${ }^{\circ} \mathrm{C}$. In flow cell studies, Daramic 175 microporous separator (thickness $=175 \mu \mathrm{m}$, porosity $=58$ $\%$, mean pore size $=100 \mathrm{~nm}$ ) was employed as the separator material. All electrochemical measurements were performed using a Biologic-VMP3 potentiostat. All quantitative results reported in figures and tables are mean values of three independent measurements, unless otherwise explicitly stated. Error bars and uncertainties represent $95 \%$ confidence intervals of the standard error, accounting for experimental uncertainties, measurement noise, and repeatability.

\subsection{Electrolyte Conductivity Measurements}

Conductivity measurements were performed by using a two-electrode Swagelok conductivity cell, similar to those employed previously in literature. [50] A schematic of the conductivity cell employed in this work is provided in Figure S1. The conductivity cell was filled with $700 \mu \mathrm{L}$ of electrolyte and sealed shut. An impedance measurement was made about the cell open circuit voltage (OCV), with an amplitude of $10 \mathrm{mV}$, over a frequency range of $1 \mathrm{MHz}$ to $100 \mathrm{~Hz}$. The high frequency intercept of the impedance curve was identified and used as the cell resistance value in subsequent calculations. Ten impedance measurements were performed for each electrolyte aliquot, and these measurements were repeated three times using a fresh electrolyte aliquot. In between measurements, the conductivity cell was rinsed with pure PC. The conductivity cell was calibrated using aqueous conductivity standards, and nonaqueous electrolyte conductivities were determined from total cell resistance measurements and the calibration curve. The following aqueous conductivity standards (Orion ${ }^{\mathrm{TM}}$ ) were used to build a four-point calibration curve in an ice-water bath $\left(0{ }^{\circ} \mathrm{C}\right): 100 \mu \mathrm{S} \mathrm{cm}^{-1}, 1.413 \mathrm{mS} \mathrm{cm}{ }^{-1}, 12.90 \mathrm{mS} \mathrm{cm}^{-1}$, and $111.9 \mathrm{mS} \mathrm{cm}^{-1}$.

\subsection{Viscosity, Density, and UV-vis Measurements}

A vibrational viscometer probe (Viscolite V-700) was used to measure the viscosity of $15 \mathrm{~mL}$ electrolyte samples held in glass scintillation vials. Three viscosity measurements were made for each electrolyte composition for one vial of fresh electrolyte. Electrolyte density measurements were performed in triplicate using a balance (Metler-Toledo XP105) and known electrolyte 
volume. Electrolyte densities were required for viscosity measurements. UV-vis measurements were performed once using a SEC2000 spectrometer (ALS Co., Ltd) with $50 \mathrm{mM}$ total active species in $0.5 \mathrm{M} \mathrm{LiBF}_{4} / \mathrm{PC}$.

\section{$2.4 \quad$ Cyclic Voltammetry}

$\mathrm{CV}$ experiments were performed in three electrode cells consisting of a $3 \mathrm{~mm}$ diameter glassy carbon working electrode ( $\mathrm{CH}$ Instruments), a gold coil counter electrode ( $\mathrm{CH}$ Instruments), and an un-fritted lithium foil pseudo-reference electrode. The three-electrode cell contained $2-5 \mathrm{~mL}$ of redox electrolyte, which was comprised of $5 \mathrm{mM}$ active material in $0.5 \mathrm{M} \mathrm{LiBF}_{4} / \mathrm{PC}$. Prior to beginning electrochemical measurements, the glassy carbon electrode was polished using $0.05 \mu \mathrm{m}$ alumina suspension, sonicated in a water bath, and rinsed with supporting electrolyte $\left(0.5 \mathrm{M} \mathrm{LiBF}_{4}\right.$ / PC). A $100 \%$ resistance compensation ( $i \mathrm{R}$ correction) was applied by the potentiostat during CV experiments. Three CV cycles were performed for each of the following scan rates: 5, 10, 20, 50, and $100 \mathrm{mV} \mathrm{s}^{-1}$. For CV experiments where scan rate was varied, three independent experiments were performed with a freshly polished glassy carbon electrode and freshly prepared redox electrolyte. In the first set of CV experiments, following the scan-rate dependence study, $100 \mathrm{CV}$ cycles were performed at a scan rate of $100 \mathrm{mV} \mathrm{s}^{-1}$; this long duration cycling experiment was performed only once.

$$
i_{p}=0.4463 n F A C\left(\frac{n F s D}{R T}\right)^{\frac{1}{2}}
$$

The Randles-Sevcik equation (Equation (1)) was used to calculate the diffusion coefficients of the active species. In Equation (1), $i_{p}$ is the peak current, $n$ is the number of electrons transferred, $A$ is the electrode surface area, $C$ is the reactant concentration, $s$ is the scan rate, $R$ is the universal gas constant, $T$ is temperature, and $D$ is the diffusion coefficient. [51] For quantitative $C V$ analysis, only the second cycle was considered. Peak currents $\left(i_{p}\right)$ were background corrected using a technique previously employed in literature. [8,52] Redox (half-wave) potentials $\left(E^{\circ}\right)$ were calculated as the mean potential between $\mathrm{CV}$ peaks.

\subsection{Symmetric Flow Cell Cycling}

Symmetric flow cell cycling was carried out using a flow cell with flow-through carbon felt electrodes (GFA6, SGL Group), which was previously described by Laramie et al. [53] The 
separator material was two layers of Daramic 175. The flow cell was first assembled outside the glove box and then dried under vacuum $(-91 \mathrm{kPag})$ at room temperature for at least $1 \mathrm{~h}$ before beginning electrochemical measurements inside the glove box. Glass scintillation vials served as the reservoirs each filled with $10 \mathrm{~mL}$ of redox electrolyte. A peristaltic pump (Masterflex $\mathrm{L} / \mathrm{S}$ Series) with Norprene tubing (Masterflex, $1.6 \mathrm{~mm}$ inner diameter) drove redox electrolyte through the flow cell at $5 \mathrm{~mL} \mathrm{~min}^{-1}$. The positive reservoir contained a redox electrolyte of $50 \mathrm{mM} \mathrm{AcNH}-$ TEMPO / $0.5 \mathrm{M} \mathrm{LiBF}_{4}$ / PC, while the negative reservoir contained $50 \mathrm{mM} \mathrm{AcNH-TEMPO}{ }^{+} / 0.5$ $\mathrm{M} \mathrm{LiBF}_{4} /$ PC. A constant current density of $2 \mathrm{~mA} \mathrm{~cm}^{-2}(9.270 \mathrm{~mA})$, calculated from the geometric electrode area $\left(4.635 \mathrm{~cm}^{2}\right)$, was applied during cycling, and cell potential cutoffs of $-0.4 \mathrm{~V}$ to 0.4 $\mathrm{V}$ were imposed. Individual charge (or discharge) half-cycles required $\sim 1.25 \mathrm{~h}$ to complete, and 20 full cycles completed in $51 \mathrm{~h}$.

\subsection{Single Electrolyte Flow Cell Experiments}

A small volume, custom flow cell (Figure S2) employing an interdigitated flow field was used in single electrolyte diagnostic experiments. The flow field was machined from $3.18 \mathrm{~mm}$ thick impregnated graphite (G347B graphite, MWI, Inc.). The end plates were machined from polypropylene, which was selected due to its chemical compatibility with PC. Electrodes were cut from $300 \mu \mathrm{m}$ thick carbon paper (35 AA, SGL Group), and compressed by $15.3 \%$ in the assembled flow cell, providing a geometric active area of $2.25 \mathrm{~cm}^{2}$. A single layer of Daramic 175 served as the separator. Teflon gaskets sealed the separator and electrodes into the cells. Flow cells were initially assembled outside the glove box, and were then dried for at least $1 \mathrm{~h}$ under vacuum (-91 $\mathrm{kPag}$ ) before beginning electrochemical testing. All flow cell polarization and impedance measurements were performed inside the glove box.

A single $10 \mathrm{~mL}$ sealed jar (Savillex), made from perfluoroalkoxy alkane (PFA), was filled with

redox electrolyte, which was carried into the flow cell at a variable flow rate. A peristaltic pump (Masterflex L/S Series) with a high performance pump head (Masterflex) was used to drive redox electrolyte from the reservoir to the flow cell. PharMed BPT tubing (Masterflex) was used inside the peristaltic pump head, while PFA tubing (Swagelok) connected the pump head, reservoir, and flow cell together. All tubing had an inner diameter of $1.6 \mathrm{~mm}$, and all tubing connections were coupled together with pressure rated PFA or stainless steel compression fittings. 
Redox electrolytes were comprised of 0.25 M AcNH-TEMPO / 0.25 M AcNH-TEMPO / 1 $\mathrm{M} \mathrm{LiBF}_{4}$ / PC. $10 \mathrm{~mL}$ of redox electrolyte was pumped into the flow cell system. The theoretical capacity of this electrolyte was $134 \mathrm{mAh}\left(13.4 \mathrm{Ah} \mathrm{L}^{-1}\right)$. Impedance measurements were recorded about the OCV, with an amplitude of $10 \mathrm{mV}$, over a frequency range of $200 \mathrm{kHz}$ to $5 \mathrm{mHz}$. Polarization measurements were performed by initiating potentiostatic holds for $2 \mathrm{~min}$ in $50 \mathrm{mV}$ steps from $0-0.5 \mathrm{~V}$. Data points were recorded every $1 \mathrm{~s}$, and the mean current and potential values of the final $75 \%$ of data points were used in the final I-V curves. Impedance and polarization measurements were performed at redox electrolyte flow rates of 2 and $10 \mathrm{~mL} \mathrm{~min}^{-1}$.

\section{Results and Discussion}

\subsection{State of Charge Dependent Solution Properties}

Stock redox electrolytes consisting of $0.5 \mathrm{M}$ total active species in $1 \mathrm{M} \mathrm{LiBF}_{4} / \mathrm{PC}$ at 5 different SOCs demonstrate variations in redox electrolyte properties as a function of SOC. Although we did not measure solubility limits of AcNH-TEMPO or AcNH-TEMPO ${ }^{+}$, we found both species to be soluble to at least $0.5 \mathrm{M}$ in our supporting electrolyte of interest ( $1 \mathrm{M} \mathrm{LiBF}_{4} / \mathrm{PC}$ ), which is a comparable concentration to state-of-the-art literature engaging in nonaqueous flow cell studies. $[10,14,22,54]$ A digital photograph of these redox electrolytes (Figure S3) shows a marked change in solution color as a function of SOC. To quantify this color change, dilute solutions containing $50 \mathrm{mM}$ active species and $0.5 \mathrm{M} \mathrm{LiBF}_{4}$ in PC undergo a UV-vis study. Figure 2a shows UV-vis spectra in the wavelength $(\lambda)$ range of interest for AcNH-TEMPO solutions as a function of SOC;

note the characteristic spectral peaks at $\lambda=460$ and $479 \mathrm{~nm}$. The absolute absorbance in the range of interest increases in magnitude across all wavelengths as SOC increases, and the peak at 479 $\mathrm{nm}$ grows slightly faster $(8 \%)$ than the peak at $460 \mathrm{~nm}$. The presence of two distinct spectral features allows for construction of calibration curves, at two different wavelengths, to correlate absorbance with SOC. Figure $2 \mathrm{~b}$ plots the absorbance at $\lambda=460$ and $479 \mathrm{~nm}$ as a function of SOC. Linear best-fit lines achieve $r$-squared values $>0.999$, suggesting that UV-vis could monitor SOC of AcNH-TEMPO-based redox electrolytes during electrochemical experiments. 

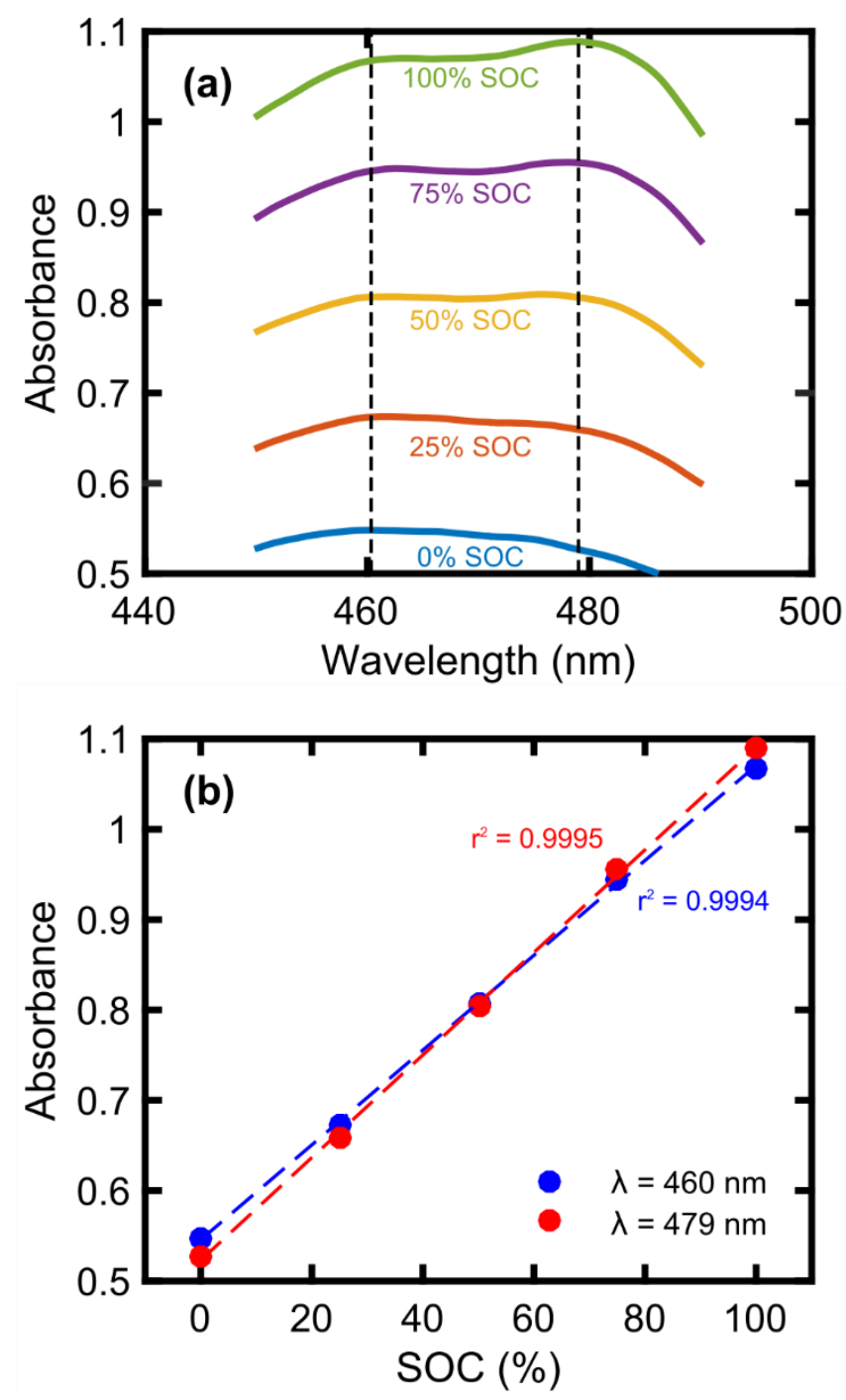

Figure 2: UV-vis absorbance spectra of (a) AcNH-TEMPO redox electrolytes at 5 SOCs (0 \%, $25 \%, 50$ $\%, 75 \%$, and $100 \%$ ), and (b) absorbance spectra as a function of SOC at wavelengths of 460 and $479 \mathrm{~nm}$. Redox electrolytes for UV-vis spectra measurements are comprised of $50 \mathrm{mM}$ total active species in $0.5 \mathrm{M}$ $\mathrm{LiBF}_{4} / \mathrm{PC}$.

After investigating the spectral properties of AcNH-TEMPO solutions, the redox electrolytes depicted in Figure S3 are utilized to perform further measurements of other physicochemical solution properties as a function of SOC, namely ionic conductivity (Figure 3a) and viscosity (Figure 3b). Figure S1 tabulates the conductivities, viscosities, and densities of all electrolytes considered, as well as the pure solvent (PC) and the supporting electrolyte (1 $\left.\mathrm{M} \mathrm{LiBF}_{4} / \mathrm{PC}\right)$. As a 
check to the experimental methods employed in this work, the conductivity and viscosity values of the $1 \mathrm{M} \mathrm{LiBF}_{4}$ / PC supporting electrolyte agree with prior literature. [55]

Both the conductivity and viscosity of AcNH-TEMPO redox electrolytes increase monotonically as a function of SOC. Typically, increases in viscosity correlate with decreases in ionic conductivity due to lower mobility of the charge carrying species. In the case of AcNHTEMPO redox electrolytes, the ionic strength increases as a function of SOC; the active species oxidizes from a neutral molecule to a cation, bringing an associated $\mathrm{BF}_{4}{ }^{-}$counter-ion. Increasing ionic strength with increasing SOC yields a subsequent increase in conductivity, despite a corresponding increase in solution viscosity. As compared to the supporting electrolyte, solutions containing AcNH-TEMPO exhibited lower conductivities. Additional inter-molecular forces (higher ionic strength) and additional solute (higher $\mathrm{BF}_{4}^{-}$concentration) likely cause solution viscosity increase with SOC. Viscosities of the redox electrolytes are also higher than the viscosities of the supporting electrolyte or the pure solvent. While redox electrolyte conductivity only varies by $13 \%$ across all SOCs, the viscosity swings by $45 \%$ from $0-100 \%$ SOC. The AcNH-TEMPO redox pair offers a tool for experimentally studying how changes in viscosity may affect mass transport and pumping losses in a flow cell as a function of SOC. 

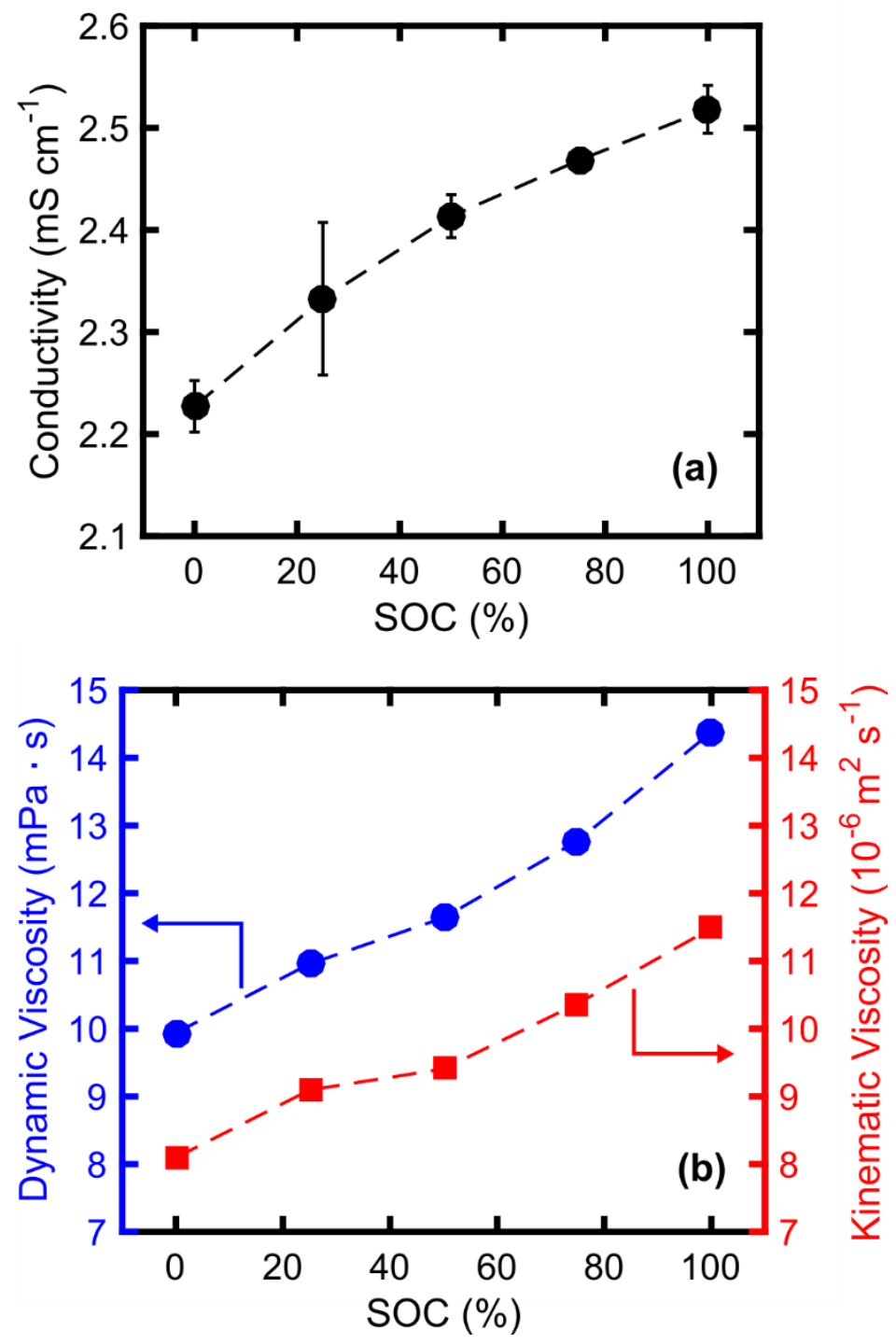

Figure 3: (a) Conductivities, and (b) dynamic and kinematic viscosities of $0.5 \mathrm{M}$ total active species in 1 $\mathrm{MLiBF}_{4} / \mathrm{PC}$ as functions of SOC $(0 \%, 25 \%, 50 \%, 75 \%$, and $100 \%) .95 \%$ confidence intervals represent the experimental uncertainty calculated from 3 independent measurements. Confidence intervals for viscosity measurements are too small to see on either y-scale of the plot.

\subsection{Cyclic Voltammetry}

$\mathrm{CV}$ provides a method of investigating the redox potential, kinetics, and diffusion coefficients associated with the AcNH-TEMPO couple. Figure $4 \mathrm{a}$ and Figure $4 \mathrm{~b}$ show CVs of AcNH-TEMPO and $\mathrm{AcNH}-\mathrm{TEMPO}^{+}$, respectively, at varying scan rates. Ideally, for a model compound, the redox potential would be well within the electrochemical window of common organic electrolytes, $[15,16]$ allowing for controlled studies that are not convoluted by electrolyte decomposition. The 
redox potential is $E^{o}=3.63 \mathrm{~V} \mathrm{vs}$. $\mathrm{Li} / \mathrm{Li}^{+}$, which is within the bounds of the electrochemical stability window of this electrolyte system. Across three repeat experiments of five CV scan rates, the cathodic peak potential of AcNH-TEMPO is $3.664 \pm 0.002 \mathrm{~V}$ vs. $\mathrm{Li} / \mathrm{Li}^{+}$, and the anodic peak potential is $3.602 \pm 0.002 \mathrm{~V}$ vs. $\mathrm{Li}^{2} / \mathrm{Li}^{+}$. Similarly, the cathodic peak potential of AcNH-TEMPO ${ }^{+}$ is $3.664 \pm 0.002 \mathrm{~V}$ vs. $\mathrm{Li} / \mathrm{Li}^{+}$, and the anodic peak potential is $3.602 \pm 0.001 \mathrm{~V}$ vs. $\mathrm{Li} / \mathrm{Li}^{+}$. Additionally, the peak current ratios for AcNH-TEMPO and AcNH-TEMPO ${ }^{+}$are identical and equal to $1.01 \pm 0.14$ across all scan rates and replicate experiments. The lack of change in peak potential and peak current ratios as a function of scan rate for both the neutral radical and cation salt indicates that the AcNH-TEMPO redox pair is electrochemically reversible under the CV experimental conditions. Furthermore, Figure $4 c$ and Figure $4 d$ show CVs of AcNH-TEMPO and $\mathrm{AcNH}^{-\mathrm{TEMPO}^{+}}$, respectively, for the $2^{\text {nd }}$ and $100^{\text {th }}$ cycles, at a scan rate of $100 \mathrm{mV} \mathrm{s}^{-1}$. The $\mathrm{CV}$ behavior is identical over 100 cycles, indicating that AcNH-TEMPO is stable on the CV time scale. 

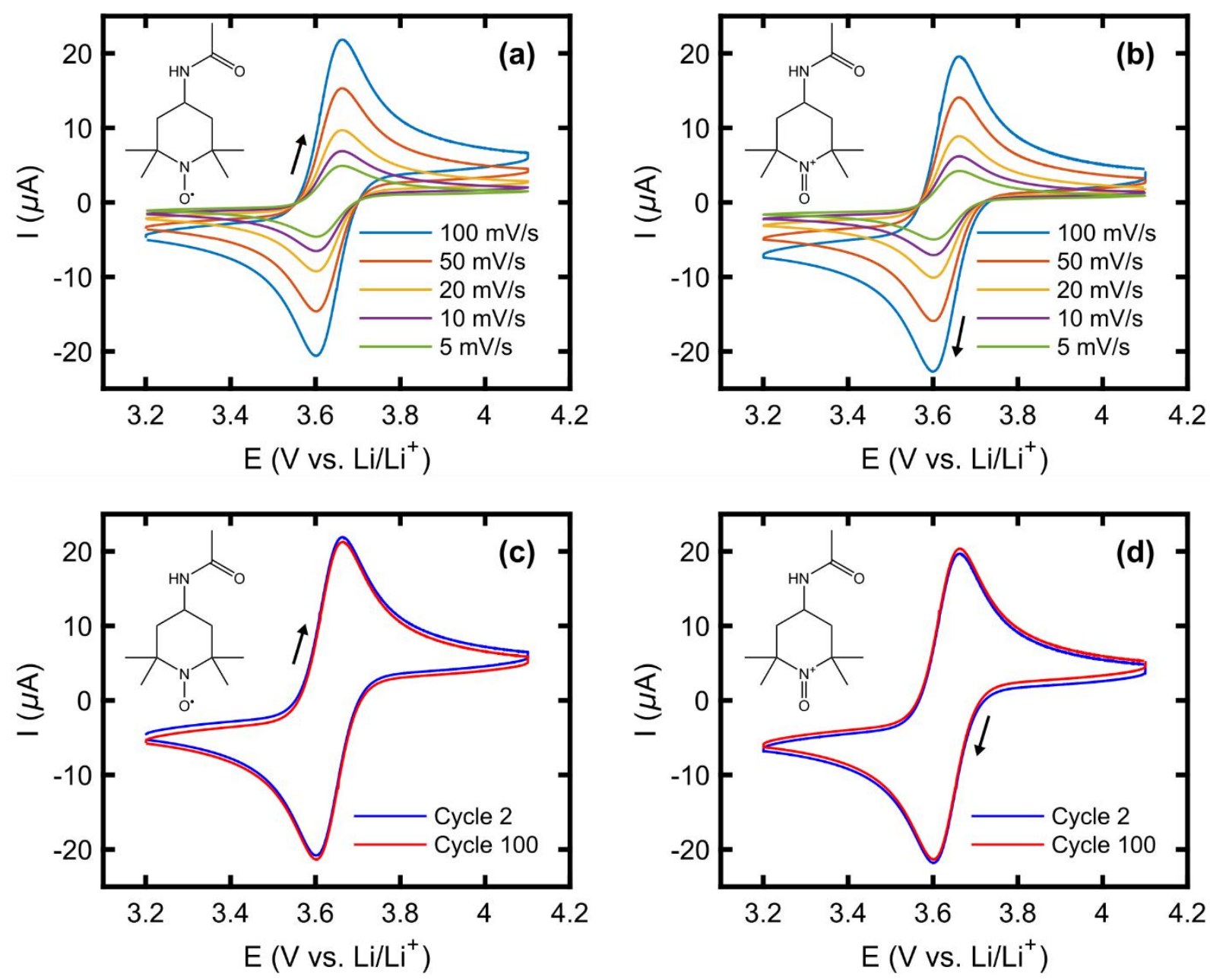

Figure 4: CVs (cycle 2) at various scan rates $\left(5,10,20,50\right.$, and $100 \mathrm{mV} \mathrm{s}^{-1}$ ) for (a) AcNH-TEMPO and (b) $\mathrm{AcNH}_{-} \mathrm{TEMPO}^{+}$, and extended CV cycling over 100 cycles (at $100 \mathrm{mV} \mathrm{s}^{-1}$ ) for (c) AcNH-TEMPO and (d) AcNH-TEMPO ${ }^{+}$. Active species concentration was $5 \mathrm{mM}$ and the supporting electrolyte composition was $0.5 \mathrm{M} \mathrm{LiBF}_{4}$ / PC. Arrows indicate the initial scan direction.

From the scan-rate dependence CV study, we calculated the diffusion coefficients of dilute AcNH-TEMPO and AcNH-TEMPO ${ }^{+}$using Randles-Sevcik analysis (Equation (1)). The diffusion coefficients of both the reduced $\left(D_{R}\right)$ and oxidized $\left(D_{O}\right)$ species are identical within experimental uncertainty $\left(D_{R}=D_{O}=4.3 \times 10^{-7} \mathrm{~cm}^{2} \mathrm{~s}^{-1}\right)$. The analysis in Figure S4 demonstrates a linear dependence of peak current as a function of square root of scan rate, leading to facile determination of diffusion coefficients at low active species concentrations. 


\subsection{Symmetric Flow Cell Cycling}

A symmetric flow cell experiment allows for cycling of both the reduced and oxidized species in the AcNH-TEMPO redox pair to determine the active species stability without the presence of additional compounds. Some recent investigations into active material stability for NAqRFBs used bulk electrolysis cycling containing $\leq 5 \mathrm{mM}$ active species and a sacrificial counter electrode isolated from the reaction of interest by a porous glass frit. [8,53] The symmetric flow cell technique offers a more controlled electrolyte environment by removing the need for a counter electrode of dissimilar material, eliminating the possibility of side-product species crossing over from the counter electrode chamber and contaminating the working electrode. The flowing electrolyte also improves mass transfer, enabling higher concentration cycling studies, and investigates active material stability on porous carbon electrodes relevant to flow battery applications instead of reticulated vitreous or glassy carbon.

Figure 5a shows a schematic of the symmetric flow cell, where AcNH-TEMPO serves as the starting positive redox electrolyte material and $\mathrm{AcNH}-\mathrm{TEMPO}^{+}$is the starting negative redox electrolyte material. In this configuration, the redox active species on either side of the cell oscillates between AcNH-TEMPO and $\mathrm{AcNH}-\mathrm{TEMPO}^{+}$, shuttling $\mathrm{BF}_{4}{ }^{-}$anions across the separator to balance charge. As such, the symmetric flow cell technique offers a controlled method of cycling only the active species of interest. Figure $5 \mathrm{~b}$ shows representative charge and discharge curves for the symmetric cell, which exhibit single plateaus corresponding to the $1 \mathrm{e}^{-}$transfer electrochemical process outlined in Figure 1. Figure 5c displays capacities and current efficiency as a function of cycle number, illustrating the stability of the AcNH-TEMPO redox pair, even after deep charging where $>81 \%$ of the theoretical capacity is accessed during every charge cycle. The mean current efficiency is 99.4 ( \pm 0.6$) \%$, and, after 20 cycles, the capacity faded to just $92.6 \%$ of its initial value. Wei et al. reported a nearly identical fade rate of $~ 91 \%$ for a $0.1 \mathrm{M}$ TEMPO / lithiumhybrid flow cell, [10] suggesting that AcNH-TEMPO exhibits similar stability to its parent molecule. The capacity retention of AcNH-TEMPO in $\mathrm{LiBF}_{4} / \mathrm{PC}$ lends this redox electrolyte system to diagnostic flow cell experiments, where active species decay can be ruled out as a major performance degradation mechanism. 

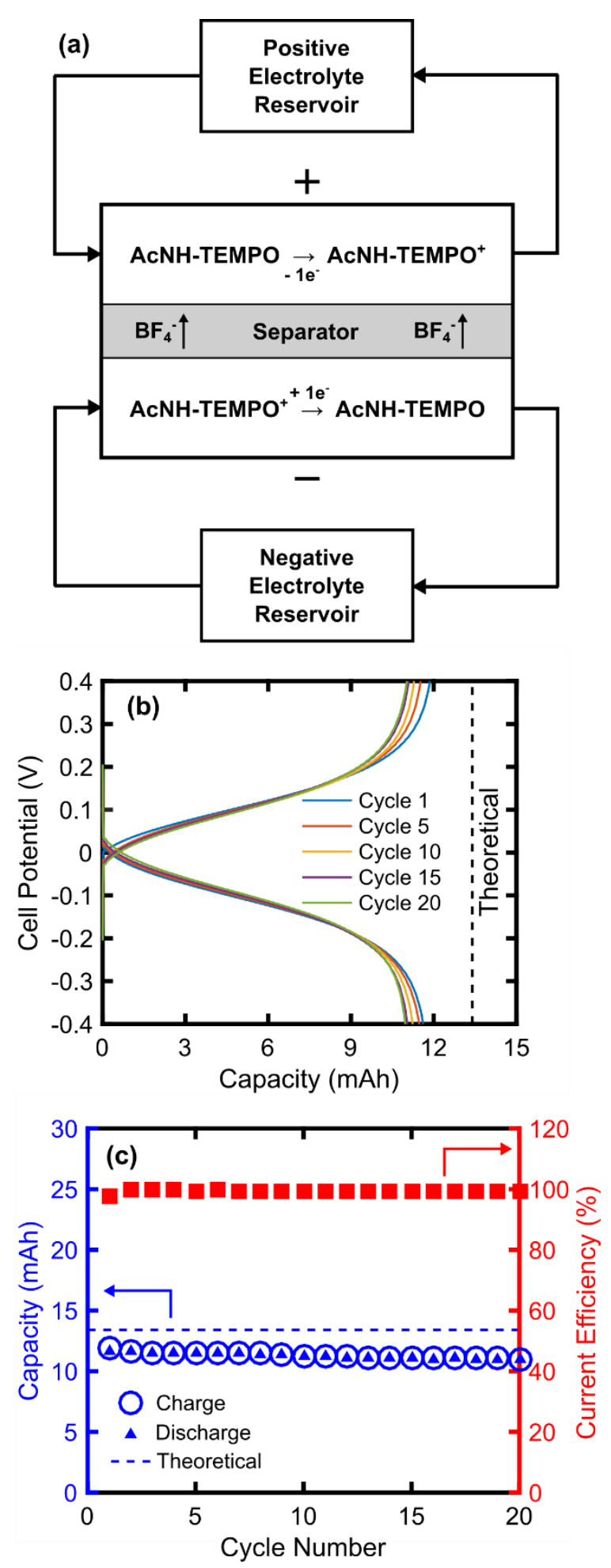

Figure 5: (a) Schematic of the AcNH-TEMPO symmetric flow cell during charging. (b) Potential curves for symmetric cell cycling of $50 \mathrm{mM}$ total active species in $0.5 \mathrm{M} \mathrm{LiBF}_{4}$ / PC including cycle numbers: 1 , 5, 10, 15, and 20. (c) Charge (blue O), discharge (blue $\mathbf{A}$ ), and theoretical (blue dashed line) capacities, as 
well as current efficiencies (red $\mathbf{\square})$, as a function of cycle number. Theoretical capacity is $13.40 \mathrm{mAh}(1.34$ $\left.\mathrm{Ah} \mathrm{L}^{-1}\right)$.

\subsection{Single Electrolyte Flow Cell}

To illustrate the value of a model redox active species for evaluating NAqRFBs, we employ a single electrolyte flow cell experiment to characterize cell performance. Figure 6a depicts a flow cell reactor in which one electrolyte stream circulates through both electrodes, and $\mathrm{BF}_{4}^{-}$anions transfer across the separator to balance the electrochemical reactions. The active species oxidizes at the anode and then reduces at the cathode, before returning to the reservoir. Thus, the SOC in the reservoir should not vary with time. In this configuration, the cell operates at steady state over a wide range of flow rates and current densities. [18] Furthermore, crossover effects do not degrade the performance of the single electrolyte flow cell because the same electrolyte composition is present on both sides of the cell, and this technique offers simple cell-level analysis, without reference electrodes, since nearly identical processes occur on both sides of the cell. [17] Here, an AcNH-TEMPO model redox electrolyte, at $50 \%$ SOC, fills the flow cell to explore NAqRFB reactor performance.

Figure $6 \mathrm{~b}$ shows polarization curves for the AcNH-TEMPO single electrolyte cell at two different flow rates, 2 and $10 \mathrm{~mL} \mathrm{~min}^{-1}$. The polarization measurements achieve current densities on par with the highest current density achieved in NAqRFB cycling experiments to date (20 mA $\mathrm{cm}^{-2}$ ). [14] The slopes of the polarization curves are equivalent to the reactor area-specific resistances (ASR). The polarization curves show that by increasing flow rate, the total cell ASR decreases, likely due to enhanced reactant transport to the porous electrode surface. The ASR values calculated from Figure $6 \mathrm{~b}$ are quite high in comparison to typical aqueous RFBs, but are on par with previous NAqRFBs reports. For example, a recent study demonstrated an all-organic NAqRFB with an ASR of $23.2 \Omega \mathrm{cm}^{2}$, employing an active species concentration of $0.5 \mathrm{M}$. [56] By comparison, Escalante-Garcia et al. demonstrated a NAqRFB employing $0.1 \mathrm{M}$ vanadium acetylacetonate as the active species achieved an ASR as low as $6.1 \Omega \mathrm{cm}^{2}$, [57] however, the lower active species concentration and acetonitrile solvent employed in that study do not compare well with the present work. Impedance data will illustrate that the AcNH-TEMPO single electrolyte cell confirms an assumption of previous modeling reports, $[7,58]$ that separator resistivity dominates nonaqueous flow cell ASR. 

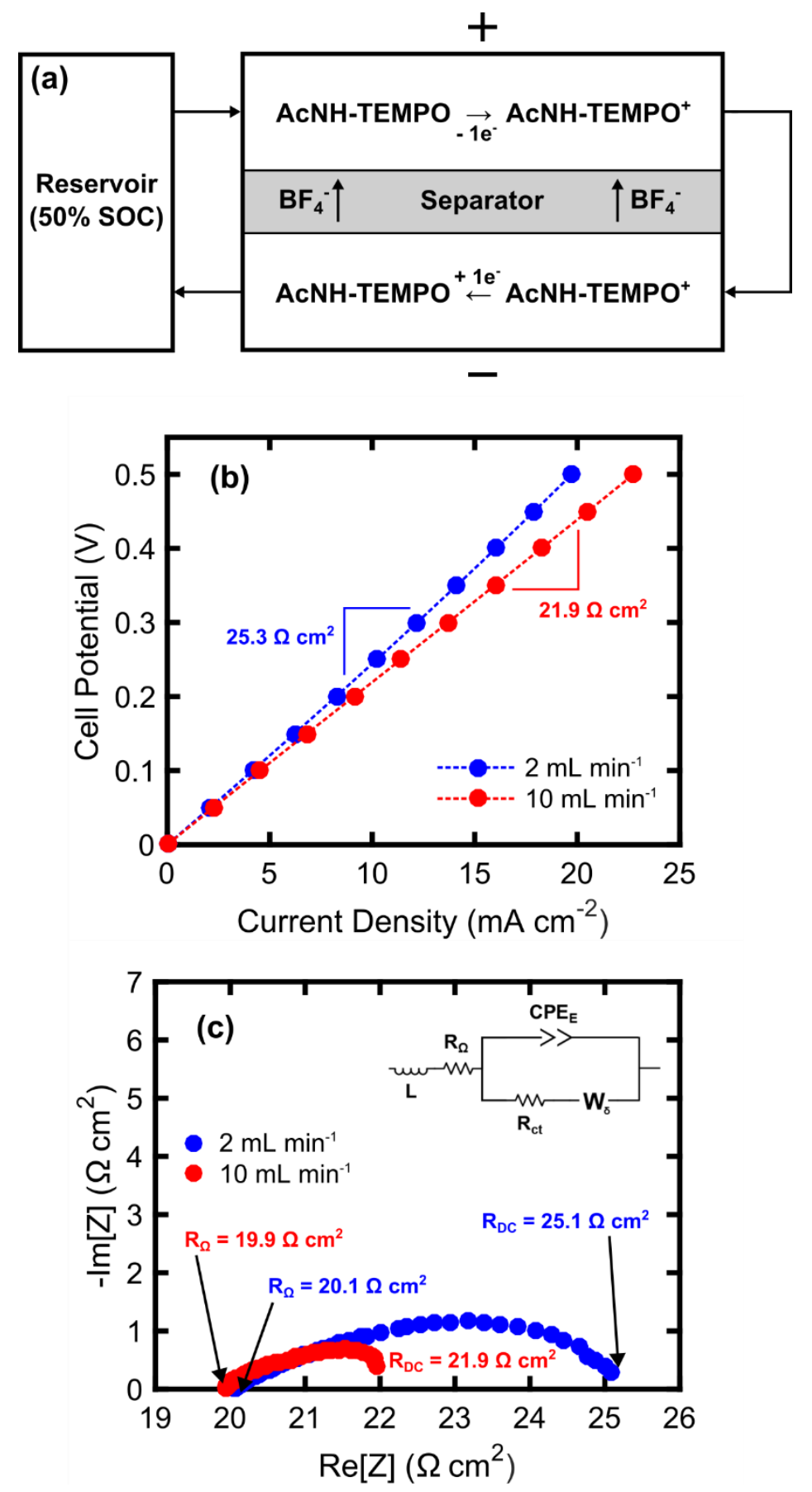

Figure 6: (a) Single electrolyte flow cell configuration for the AcNH-TEMPO / AcNH-TEMPO ${ }^{+}$couple at $50 \%$ SOC. (b) Polarization curves and (c) Nyquist plots of the flow cell at 2 and $10 \mathrm{~mL} \mathrm{~min}{ }^{-1}$. Redox electrolyte composition was 0.25 M AcNH-TEMPO / $0.25 \mathrm{M} \mathrm{AcNH-TEMPO}^{+} / 1 \mathrm{M} \mathrm{LiBF}_{4}$ / PC.

While successfully demonstrating overall flow cell performance, the linear polarization curve is difficult to break down into performance limiting processes. Electrochemical impedance 
spectroscopy adds detail to the description of reactor performance. Figure 6c presents Nyquist plots of the AcNH-TEMPO single electrolyte flow cell. For both flow rates, the Nyquist plot displays depressed semicircles caused by the capacitive effects of the porous electrode, often described by a constant phase element $\left(C P E_{E}\right)$. [59] The low frequency intercept denotes the total direct current (DC) resistance contribution $\left(R_{D C}\right)$ to the impedance, and matches almost exactly the ASR values calculated from the slopes of the polarization curves in Figure 6b. Thus, for this system, the low frequency intercept on the Nyquist plot is a good measure of the cell ASR. Since the ASR determined from the low frequency intercept, measured about OCV, is in excellent agreement with the ASR determined from the slope of the linear polarization curve, similar processes must dominate the ASR for all cell potentials considered in the experiment. The high frequency intercept $\left(R_{\Omega}\right)$ denotes the ohmic contribution to the impedance, considering the resistance of the separator, electrodes, and current collectors. Both curves on the Nyquist plot are for the same cell under different flow conditions, so $R_{\Omega}$ should be the same. Indeed, $R_{\Omega}$ is $20.0 \pm$ $0.1 \Omega \mathrm{cm}^{2}$ for both flow conditions. The ohmic impedance contribution accounts for $80.0 \%$ and $90.1 \%$ of the total ASR for the experiments at 2 and $10 \mathrm{~mL} \mathrm{~min}^{-1}$, respectively. This finding indicates that the major contribution to cell impedance is the ohmic portion, likely due to the relatively thick Daramic separator $(175 \mu \mathrm{m})$ employed in this demonstration study. For future NAqRFB prototypes, the effective ASR contribution from the separator or membrane must decrease to improve flow cell performance and lower reactor cost contributions to NAqRFB prices. $[7,50,58,60]$

Even though separator resistance dominates the ASR, the Nyquist plots (Figure 6c) indicate critical behavior as a function of flow rate as the low frequency semicircle shrinks in magnitude with increasing flow rate. A bounded Warburg element $\left(W_{\delta}\right)$, which describes a linear diffusion transport limitation through a homogenous boundary layer of finite thickness, can represent the semicircular mass transport impedance exhibited in Figure 6c. [59] Other impedance studies on flow batteries describe mass transport resistance in this manner. $[57,61]$ The decrease in the diameter of the impedance semicircle with increasing flow rate, combined with the facile reaction kinetics of AcNH-TEMPO, suggests that mass transport losses constitute a significant portion of the remaining contribution to the ASR. Note that charge transfer resistance, $R_{c t}$, is negligible in this system due to the extremely fast reaction kinetics $\left(1.0 \times 10^{-1} \geq k_{0} \geq 2.3 \times 10^{-2} \mathrm{~cm} \mathrm{~s}^{-1}\right)$ for TEMPO and its derivatives in nonaqueous electrolytes. [37,49] Figure $6 \mathrm{c}$ also presents a proposed 
equivalent circuit for this system, which considers all of the impedance elements discussed, and an inductor, $L$, to capture the impedance of the potentiostat leads. [59] A recent literature report on a symmetric NAqRFB suggested a similar equivalent circuit. [57]

\section{Conclusion}

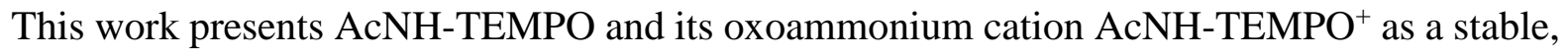
reversible and soluble active species for probing redox electrolyte properties and cell performance for NAqRFBs. First, a physicochemical study investigates the conductivity, viscosity, and density as a function of SOC for redox electrolytes containing $0.5 \mathrm{M}$ total active material in $1 \mathrm{M} \mathrm{LiBF}_{4}$ / PC; both conductivity and viscosity of the redox electrolyte increase with SOC. Also, a UV-vis study of $50 \mathrm{mM}$ total active material in $0.5 \mathrm{M} \mathrm{LiBF}_{4} / \mathrm{PC}$ exhibits two characteristic peaks, clearly demonstrating spectral changes as a function of SOC. Second, CV analysis demonstrates that the AcNH-TEMPO redox pair undergoes an electrochemically reversible one-electron transfer process at $3.63 \mathrm{~V}$ vs. $\mathrm{Li} / \mathrm{Li}^{+}$and is stable on the $\mathrm{CV}$ time scale. A symmetric flow cell configuration further assesses the stability of the redox pair to demonstrate capacity retention over multiple cycles and hours. Third and finally, a single electrolyte flow cell studies steady state cell performance, via polarization and impedance measurements, to quantify overall cell ASR and to identify performance-limiting factors. In summary, the AcNH-TEMPO redox pair offers a practical tool for systematic investigation of redox electrolyte properties and cell geometry on the performance of NAqRFBs. Combining measurements of physicochemical redox electrolyte properties with variations in flow cell ASR could yield correlations between flow cell performance and solution properties, and such an understanding could enable bottom-up engineering to optimize electrolyte properties or tailor flow cell architecture for a particular electrolyte. As such, future studies will exploit AcNH-TEMPO to evaluate cell-level performance as a function of NAqRFB reactor design and redox electrolyte properties.

\section{Acknowledgements}

This work was funded by the Joint Center for Energy Storage Research (JCESR) managed by Argonne National Laboratory. Jarrod Milshtein acknowledges the financial support of the National Science Foundation Graduate Research Fellowship Program. We would like to thank the JCESR Flow Chemistry Sprint team for their continued input and feedback, including Dr. Xiaoliang Wei, Dr. Rama Vemuri, Dr. Wentao Duan, Dr. Levi Thompson, Dr. Krista Hawthorne, Dr. Tanya 
Breault, Sydney Laramie, Dr. Kyle Smith, Rylan Dmello, and Vinay Iyer. We also thank the assistance of researchers within the Brushett Group at MIT, including Dr. Liang Su, Dr. Emily Carino, Mr. Jeffrey Kowalski, and Mr. Thomas Carney. 


\section{References}

[1] B. Dunn, H. Kamath, J.-M. Tarascon, Electrical energy storage for the grid: a battery of choices, Science. 334 (2011) 928-935.

[2] P. Denholm, E. Ela, B. Kirby, M. Milligan, The Role of Energy Storage with Renewable Electricity Generation. NREL/TP-6A2-47187, 2010.

[3] A.Z. Weber, M.M. Mench, J.P. Meyers, P.N. Ross, J.T. Gostick, Q. Liu, Redox flow batteries: a review, J. Appl. Electrochem. 41 (2011) 1137-1164.

[4] P. Alotto, M. Guarnieri, F. Moro, Redox flow batteries for the storage of renewable energy: A review, Renew. Sustain. Energy Rev. 29 (2014) 325-335.

[5] M. Skyllas-Kazacos, M.H. Chakrabarti, S.A. Hajimolana, F.S. Mjalli, M. Saleem, Progress in flow battery research and development, J. Electrochem. Soc. 158 (2011) R55-R79.

[6] W. Wang, Q. Luo, B. Li, X. Wei, L. Li, Z. Yang, Recent progress in redox flow battery research and development, Adv. Funct. Mater. 23 (2013) 970-986.

[7] R.M. Darling, K.G. Gallagher, J.A. Kowalski, S. Ha, F.R. Brushett, Pathways to low-cost electrochemical energy storage: a comparison of aqueous and nonaqueous flow batteries, Energy Environ. Sci. 7 (2014) 3459-3477.

[8] J. Huang, L. Su, J.A. Kowalski, J.L. Barton, M. Ferrandon, A.K. Burrell, F.R. Brushett, L. Zhang, A subtractive approach to molecular engineering of dimethoxybenzene-based redox materials for non-aqueous flow batteries, J Mater Chem A. 3 (2015) 14971-14976.

[9] J. Huang, L. Cheng, R.S. Assary, P. Wang, Z. Xue, A.K. Burrell, L.A. Curtiss, L. Zhang, Liquid Catholyte Molecules for Nonaqueous Redox Flow Batteries, Adv. Energy Mater. 5 (2015) 1401782.

[10] X. Wei, W. Xu, M. Vijayakumar, L. Cosimbescu, T. Liu, V. Sprenkle, W. Wang, TEMPOBased Catholyte for High-Energy Density Nonaqueous Redox Flow Batteries, Adv. Mater. 26 (2014) 7649-7653.

[11] C.S. Sevov, R.E.M. Brooner, E. Chénard, R.S. Assary, J.S. Moore, J. Rodríguez-López, M.S. Sanford, Evolutionary Design of Low Molecular Weight Organic Anolyte Materials for Applications in Nonaqueous Redox Flow Batteries, J. Am. Chem. Soc. 137 (2015) 1446514472.

[12] F.R. Brushett, J.T. Vaughey, A.N. Jansen, An All-Organic Non-aqueous Lithium-Ion Redox Flow Battery, Adv. Energy Mater. 2 (2012) 1390-1396.

[13] A.P. Kaur, N.E. Holubowitch, S. Ergun, C.F. Elliott, S.A. Odom, A Highly Soluble Organic Catholyte for Non-Aqueous Redox Flow Batteries, Energy Technol. 3 (2015) 476-480.

[14] W. Duan, R.S. Vemuri, J.D. Milshtein, S. Laramie, R.D. Dmello, J. Huang, L. Zhang, D. Hu, V. Murugesan, W. Wang, J. Liu, R. Darling, L. Thompson, K.C. Smith, J. Moore, F.R. Brushett, X. Wei, A Symmetric Organic - Based Nonaqueous Redox Flow Battery and Its State of Charge Diagnostics by FTIR, J Mater Chem A. 4 (2016) 5448-5456.

[15] D. Aurbach, Y. Talyosef, B. Markovsky, E. Markevich, E. Zinigrad, L. Asraf, J.S. Gnanaraj, H.-J. Kim, Design of electrolyte solutions for $\mathrm{Li}$ and $\mathrm{Li}$-ion batteries: a review, Electrochimica Acta. 50 (2004) 247-254.

[16] D. Aurbach, ed., Nonaqueous Electrochemistry, Marcel Dekker, New York, 1999.

[17] R.M. Darling, M.L. Perry, The Influence of Electrode and Channel Configurations on Flow Battery Performance, J. Electrochem. Soc. 161 (2014) A1381-A1387.

[18] R.M. Darling, M.L. Perry, Half-Cell, Steady-State Flow-Battery Experiments, ECS Trans. 53 (2013) 31-38. 
[19] Q. Xu, T.S. Zhao, C. Zhang, Effects of SOC-dependent electrolyte viscosity on performance of vanadium redox flow batteries, Appl. Energy. 130 (2014) 139-147.

[20] C.L. Bird, A.T. Kuhn, Electrochemistry of the viologens, Chem Soc Rev. 10 (1981) 49-82.

[21] R.R. Gagne, C.A. Koval, G.C. Lisensky, Ferrocene as an internal standard for electrochemical measurements, Inorg. Chem. 19 (1980) 2854-2855.

[22] X. Wei, L. Cosimbescu, W. Xu, J.Z. Hu, M. Vijayakumar, J. Feng, M.Y. Hu, X. Deng, J. Xiao, J. Liu, V. Sprenkle, W. Wang, Towards High-Performance Nonaqueous Redox Flow Electrolyte via Ionic Modification of Active Species, Adv. Energy Mater. 5 (2015) 1400678.

[23] L.J. Tilley, J.M. Bobbitt, S.A. Murray, C.E. Camire, N.A. Eddy, A Revised Preparation of (4-Acetamido-2,2,6,6-tetramethylpiperidin-1-yl)oxyl and 4-Acetamido-2,2,6,6-tetramethyl1-oxopiperidinium Tetrafluoroborate: Reagents for Stoichiometric Oxidations of Alcohols, Synthesis. 45 (2013) 0326-0329.

[24] J.M. Bobbitt, M.C.L. Flores, Organic Nitrosium Salts as Oxidants in Organic Chemistry, Heterocycles. 27 (1998) 509-533.

[25] J. Zakrzewski, J. Grodner, J.M. Bobbitt, M. Karpinska, Oxidation of Unsaturated Primary Alcohols and w-Haloalkanols with 4-Acetylamino- 2,2,6,6-tetramethylpiperidine-1oxoammonium Tetrafluoroborate, Synthesis. 16 (2007) 2491-2494.

[26] M. Shibuya, M. Tomizawa, Y. Iwabuchi, Oxidative Rearrangement of Tertiary Allylic Alcohols Employing Oxoammonium Salts, J. Org. Chem. 73 (2008) 4750-4752.

[27] J.M. Bobbitt, Oxoammonium Salts. 6. 4-Acetylamino-2,2,6,6-tetramethylpiperidine-1oxoammonium Perchlorate: A Stable and Convenient Reagent for the Oxidation of Alcohols. Silica Gel Catalysis, J. Org. Chem. 63 (1998) 9367-9374.

[28] J.M. Bobbitt, N. Merbouh, Preparation of 4-acetylamino-2,2,6,6-tetramethylpiperidine-1oxoammonium tetrafluoroborate, and the oxidation of geraniol to geranial, Org. Synth. 82 (2005) 80-86.

[29] W.F. Bailey, J.M. Bobbitt, K.B. Wiberg, Mechanism of the Oxidation of Alcohols by Oxoammonium Cations, J. Org. Chem. 72 (2007) 4504-4509.

[30] N. Merbouh, J.M. Bobbitt, C. Brückner, Oxoammonium Salts. 9. Oxidative Dimerization of Polyfunctional Primary Alcohols to Esters. An Interesting $\beta$ Oxygen Effect ${ }^{\dagger}$, J. Org. Chem. 69 (2004) 5116-5119.

[31] C.B. Kelly, M.A. Mercadante, T.A. Hamlin, M.H. Fletcher, N.E. Leadbeater, Oxidation of $\alpha$-Trifluoromethyl Alcohols Using a Recyclable Oxoammonium Salt, J. Org. Chem. 77 (2012) 8131-8141.

[32] M.A. Mercadante, C.B. Kelly, J.M. Bobbitt, L.J. Tilley, N.E. Leadbeater, Synthesis of 4acetamido-2,2,6,6-tetramethylpiperidine-1-oxoammonium tetrafluoroborate and 4acetamido-(2,2,6,6-tetramethyl-piperidin-1-yl)oxyl and their use in oxidative reactions, Nat. Protoc. 8 (2013) 666-676.

[33] J.M. Bobbitt, C. Brückner, N. Merbouh, Oxoammonium-and Nitroxide-Catalyzed Oxidations of Alcohols, Org. React. (2009).

[34] R. Barhdadi, C. Comminges, A.P. Doherty, J.Y. Nédélec, S. O’Toole, M. Troupel, The electrochemistry of TEMPO-mediated oxidation of alcohols in ionic liquid, J. Appl. Electrochem. 37 (2007) 723-728.

[35] J.R. Fish, S.G. Swarts, M.D. Sevilla, T. Malinski, Electrochemistry and spectroelectrochemistry of nitroxyl free radicals, J. Phys. Chem. 92 (1988) 3745-3751.

[36] J.E. Baur, S. Wang, M.C. Brandt, Fast-scan voltammetry of cyclic nitroxide free radicals, Anal. Chem. 68 (1996) 3815-3821. 
[37] T. Suga, Y.-J. Pu, K. Oyaizu, H. Nishide, Electron-Transfer Kinetics of Nitroxide Radicals as an Electrode-Active Material, Bull. Chem. Soc. Jpn. 77 (2004) 2203-2204.

[38] R.G. Evans, A.J. Wain, C. Hardacre, R.G. Compton, An electrochemical and ESR spectroscopic study on the molecular dynamics of TEMPO in room temperature ionic liquid solvents, ChemPhysChem. 6 (2005) 1035-1039.

[39] L.M. Moshurchak, C. Buhrmester, R.L. Wang, J.R. Dahn, Comparative studies of three redox shuttle molecule classes for overcharge protection of LiFePO4-based Li-ion cells, Electrochimica Acta. 52 (2007) 3779-3784.

[40] Z. Chen, Y. Qin, K. Amine, Redox shuttles for safer lithium-ion batteries, Electrochimica Acta. 54 (2009) 5605-5613.

[41] C. Buhrmester, L.M. Moshurchak, R.L. Wang, J.R. Dahn, The Use of 2,2,6,6Tetramethylpiperinyl-Oxides and Derivatives for Redox Shuttle Additives in Li-Ion Cells, J. Electrochem. Soc. 153 (2006) A1800.

[42] H. Nishide, S. Iwasa, Y.-J. Pu, T. Suga, K. Nakahara, M. Satoh, Organic radical battery: nitroxide polymers as a cathode-active material, Electrochimica Acta. 50 (2004) 827-831.

[43] M. Suguro, S. Iwasa, Y. Kusachi, Y. Morioka, K. Nakahara, Cationic Polymerization of Poly(vinyl ether) Bearing a TEMPO Radical: A New Cathode-Active Material for Organic Radical Batteries, Macromol. Rapid Commun. 28 (2007) 1929-1933.

[44] T. Janoschka, N. Martin, U. Martin, C. Friebe, S. Morgenstern, H. Hiller, M.D. Hager, U.S. Schubert, An aqueous, polymer-based redox-flow battery using non-corrosive, safe, and lowcost materials, Nature. 527 (2015) 78-81.

[45] U.S. Schubert, J. Winsberg, S. Muench, T. Janoschka, S. Morgenstern, T. Hagemann, M. Billing, S. Hoeppener, M. Hager, F.H. Schacher, G. Hauffman, J.-F. Gohy, Polymer/Zinc Hybrid-Flow Battery Using Block Copolymer Micelles featuring a TEMPO Corona as Catholyte, Polym Chem. 7 (2016) 1711-1718.

[46] J. Winsberg, T. Janoschka, S. Morgenstern, T. Hagemann, S. Muench, G. Hauffman, J.-F. Gohy, M.D. Hager, U.S. Schubert, Poly(TEMPO)/Zinc Hybrid-Flow Battery: A Novel, "Green," High Voltage, and Safe Energy Storage System, Adv. Mater. 28 (2016) 2238-2243.

[47] T. Liu, X. Wei, Z. Nie, V. Sprenkle, W. Wang, A Total Organic Aqueous Redox Flow Battery Employing a Low Cost and Sustainable Methyl Viologen Anolyte and 4-HO-TEMPO Catholyte, Adv. Energy Mater. 6 (2015) 1501449.

[48] A. Orita, M.G. Verde, M. Sakai, Y.S. Meng, The impact of $\mathrm{pH}$ on side reactions for aqueous redox flow batteries based on nitroxyl radical compounds, J. Power Sources. 321 (2016) 126134.

[49] F. Kato, N. Hayashi, T. Murakami, C. Okumura, K. Oyaizu, H. Nishide, Nitroxide Radicals for Highly Efficient Redox Mediation in Dye-sensitized Solar Cells, Chem. Lett. 39 (2010) 464-465.

[50] N.S. Hudak, L.J. Small, H.D. Pratt, T.M. Anderson, Through-Plane Conductivities of Membranes for Nonaqueous Redox Flow Batteries, J. Electrochem. Soc. 162 (2015) A2188A2194.

[51] H. Matsuda, Y. Ayabe, Zur Theorie der Randles-Sevčikschen Kathodenstrahl-Polarographie, Z. Für Elektrochem. Berichte Bunsenges. Für Phys. Chem. 6 (1955) 494-503.

[52] J.D. Milshtein, L. Su, C. Liou, A.F. Badel, F.R. Brushett, Voltammetry study of quinoxaline in aqueous electrolytes, Electrochimica Acta. 180 (2015) 695-704. 
[53] S.M. Laramie, J.D. Milshtein, T.M. Breault, F.R. Brushett, L.T. Thompson, Performance and cost characteristics of multi-electron transfer, common ion exchange non-aqueous redox flow batteries, J. Power Sources. (2016) In Review.

[54] J. Mun, M.-J. Lee, J.-W. Park, D.-J. Oh, D.-Y. Lee, S.-G. Doo, Non-aqueous redox flow batteries with nickel and iron tris (2, 2'-bipyridine) complex electrolyte, Electrochem. SolidState Lett. 15 (2012) A80-A82.

[55] M.S. Ding, Conductivity and Viscosity of PC-DEC and PC-EC Solutions of LiBF4, J. Electrochem. Soc. 151 (2004) A40-A47.

[56] X. Wei, W. Xu, J. Huang, L. Zhang, E. Walter, C. Lawrence, M. Vijayakumar, W.A. Henderson, T. Liu, L. Cosimbescu, B. Li, V. Sprenkle, W. Wang, Radical Compatibility with Nonaqueous Electrolytes and Its Impact on an All-Organic Redox Flow Battery, Angew. Chem. Int. Ed. 54 (2015) 8684-8687.

[57] I.L. Escalante-García, J.S. Wainright, L.T. Thompson, R.F. Savinell, Performance of a NonAqueous Vanadium Acetylacetonate Prototype Redox Flow Battery: Examination of Separators and Capacity Decay, J. Electrochem. Soc. 162 (2015) A363-A372.

[58] R. Darling, K. Gallagher, W. Xie, L. Su, F. Brushett, Transport Property Requirements for Flow Battery Separators, J. Electrochem. Soc. 163 (2016) A5029-A5040.

[59] X.-Z. Yuan, C. Song, H. Wang, J. Zhang, Electrochemical impedance spectroscopy in PEM fuel cells, Fundam. Appl.-Verl. Lond. (2010).

[60] L. Su, R.M. Darling, K.G. Gallagher, W. Xie, J.L. Thelen, A.F. Badel, J.L. Barton, K.J. Cheng, N.P. Balsara, J.S. Moore, F.R. Brushett, An Investigation of the Ionic Conductivity and Species Crossover of Lithiated Nafion N117 in Nonaqueous Electrolytes, J. Electrochem. Soc. 163 (2016) A5253-A5262.

[61] C.-N. Sun, F.M. Delnick, D.S. Aaron, A.B. Papandrew, M.M. Mench, T.A. Zawodzinski, Resolving Losses at the Negative Electrode in All-Vanadium Redox Flow Batteries Using Electrochemical Impedance Spectroscopy, J. Electrochem. Soc. 161 (2014) A981-A988. 
